\title{
Planos diretores municipais de pequeno porte no Paraná: Cianorte, Rondon e São Tomé
}

\author{
Master plans of small municipalities in Parana state: \\ Cianorte, Rondon and São Tomé
}

Tomás Antonio Moreira[ ${ }^{[0]}$, Maria Inês Terbeck ${ }^{[b]}$

[a] Universidade de São Paulo (USP), Instituto de Arquitetura e Urbanismo (IAU-USP), São Carlos, SP, Brasil

[b] Secretaria de Estado do Desenvolvimento Urbano do Estado do Paraná, Curitiba, PR, Brasil

\section{Resumo}

Os instrumentos do Plano Diretor Municipal, por força de lei ou por opção de gestão, constituem importantes mecanismos de planejamento em uso atualmente. Após 13 anos de aprovação da Lei Federal no 10.257/2001, Estatuto da Cidade e 8 anos da Lei Estadual no 15.229/2006, quando praticamente todos os municípios no estado do Paraná já elaboraram seus Planos Diretores Municipais, devido à obrigatoriedade estadual. Este artigo tem como objetivo avaliar como e se a sua implementação está auxiliando os municípios em seu processo de Gestão Urbana. Os municípios de Cianorte, Rondon e São Tomé são o foco do trabalho na Mesorregião Noroeste do estado do Paraná, pelo seu peculiar processo de urbanização conduzido pela Companhia de Terras do Norte do Paraná, mais tarde Companhia Melhoramentos do Norte do Paraná. Identificou-se que ocorreram avanços significativos na aplicação da legislação e instrumentos do Estatuto da Cidade, que a existência do instrumento do Plano Diretor Municipal tem auxiliado na Gestão dos municípios. Identificou-se que os municípios pequenos, considerando-se os com população menor que 20 mil habitantes, estão implementando seus planos, resguardadas suas limitações.

Palavras-chave: Plano Diretor. Estatuto da Cidade. Municípios de pequeno porte. Urbanização. Planejamento urbano.

\section{Abstract}

The instruments of the Municipal Master Plan, by law or choice of management, are important planning mechanisms in use today. Thirteen years after federal law No. 10.257/2001 - City Statute and 8 years after state law No.15.229/2006 were passed, virtually all municipalities in the state of Paraná have developed their

TAM é Graduado em Arquitetura e Urbanismo pela Pontifícia Universidade Católica de Campinas, Campinas - Brasil (1988); Mestre em Ciências Aplicadas - orientação Habitat \& Desenvolvimento pela Université Catholique de Louvain, Louvain-la-Neuve - Bélgica (1996); Ph.D. em Estudos Urbanos pela Université du Québec à Montréal, Montreal - Canadá (2006), e-mail: tomas_moreira@sc.usp.br MIT é Arquiteta e Urbanista, pela Universidade Federal do Paraná (UFPR), Paraná - Brasil; Mestre em Gestão Urbana, diplomada pela Pontifícia Universidade Católica do Paraná (PUCPR), e-mail: ines@paranacidade.org.br 
Municipal Master Plans due to mandatory state requirement. This article aims to assess whether and how their implementation is assisting municipalities in the process of Urban Management. The municipalities of Cianorte, Rondon and São Tomé, in the mesoregion of northwestern Paraná state, are the focus of this work because of their peculiar urbanization process conducted by the "Companhia de Terras do Norte do Paraná", later "Companhia Melhoramentos do Norte do Paraná". The study identified that significant advances occurred in the application of the laws and instruments of the City Statute, and that the existence of the Master Plans have assisted in the management of the municipalities investigated. It was possible to identify that small municipalities, with populations smaller than 20,000 inhabitants, are also implementing their master plans, respecting their own limitations.

Keywords: Master Plan. Statute of the City. Small municipalities. Urbanization. Urban planning.

\section{Planos diretores para municípios de pequeno porte}

O estado do Paraná foi um dos pioneiros no processo de elaboração de planos diretores para municípios com população abaixo de 20 mil habitantes, após a aprovação do Estatuto da Cidade, em 2001. 0 Estado implementou uma política que visava à aplicação da totalidade dos seus 399 municípios. Seu intuito era compor não apenas o planejamento municipal para as cidades de porte acima de 20 mil habitantes, como recomendado pelo Estatuto da Cidade, mas, sobretudo, estruturar uma política estadual (Meirelles, 1985; Cymbalista \& Bueno, 2007; Santos \& Montandon, 2011). Entre os fatores que contribuíram para esta política, consta o processo de planejamento do estado, que levou muitos municípios paranaenses a elaborarem, durante os anos de 1980 e 1990, os seus Planos de Uso e Ocupação do Solo (PLUOS), que contemplavam um rol mínimo de leis urbanísticas (Famepar, 1992).

Com a aprovação do Estatuto da Cidade em 2001, a maioria dos municípios que elaboraram seus Planos Diretores Municipais no Paraná são de pequeno porte, num total de 281 (Brasil, 2004; ParanaCidade, 2012a, 2012c). Como a maioria dos instrumentos do Estatuto da Cidade estavam relacionados e contemplaram processos de planejamento característicos de municípios de médio e grande porte, os pequenos municípios sofreram com a falta de diretrizes e instrumentos para orientar seu desenvolvimento (Bacellar de Araújo \& Bezerra, 1999). Estes tiveram que construir seu referencial para cuidar de seu território, apoiando-se muitas vezes sobre os PLUOS já elaborados (Faraco, 2010). No estado do Paraná, a obrigatoriedade de elaboração dos planos diretores foi ampliada para todos os municípios que objetivavam obter linhas de financiamento do Governo do Estado, a partir da aprovação do Decreto Estadual no 2581 de 17 de fevereiro de 2004, substituído pela Lei 15.229 de 25 de julho de 2006 (Paraná, 2006). Sob esta visão, o estado do Paraná, ao tomar a iniciativa de ampliar a obrigatoriedade de elaboração de planos diretores, estimulou os municípios a cumprirem sua atribuição constitucional, de exercer o controle sobre o uso e ocupação de seu solo.

Em 2009, foi realizada uma pesquisa no estado do Paraná, em parceria do Laboratório de Arquitetura e Urbanismo (LAURB) da UFPR e com o Observatório de Políticas Públicas, tendo sido avaliados 33 planos diretores, distribuídos em diferentes regiões. Desta pesquisa resultou que dos 399 municípios, 240 deles já o possuíam e 125 estavam em elaboração. Dos 33 municípios selecionados, 31 tinham mais de 20 mil habitantes, sendo que dois possuíam menos de 20 mil habitantes e seis pertenciam à Região Metropolitana de Curitiba (Paranacidade, 2003a, 2003b). É evidente a escassez de analise sobre municípios de pequeno porte.

Em novembro de 2012, dos 339 municípios paranaenses, 363 já tinham concluído seu plano diretor, 26 estavam em andamento e apenas 10 municípios ainda não tinham iniciado seu plano diretor (ParanaCidade, 2012a, 2012b). Diante deste quadro, o objetivo deste artigo é analisar os planos diretores em municípios de pequeno porte, ilustrando por meio de três estudos de caso de municípios na Mesorregião Noroeste do Estado do Paraná. 


\section{Municípios avaliados: Cianorte, Rondon e São Tomé}

Como estudos de caso foram definidos três municípios: Cianorte, Rondon e São Tomé, localizados na Mesorregião Noroeste do estado do Paraná (Figura 1). Os critérios de seleção levaram em conta o peculiar processo de urbanização conduzido pela Companhia de Terras do Norte do Paraná (CTNP), bem como a concentração de municípios de pequeno porte nesta região.

A Companhia de Terras do Norte do Paraná (CTNP), de origem inglesa, planejou um conjunto de cidades articuladas entre si. A CTNP transformou-se mais tarde na Companhia de Melhoramentos do Norte do Paraná (CMNP). Segundo Endlish, (2009, p. 70), nos planos desta Companhia, o espaço deveria estar organizado de maneira que os núcleos urbanos pudessem atender às necessidades de uma densa população rural.

A escolha da Mesorregião Noroeste do Estado do Paraná, constituída pelas Microrregiões de Paranavaí,
Umuarama e Cianorte, que possui 61 municípios, deve-se ao que no início dos anos 1970 era a segunda Mesorregião mais populosa do interior do Paraná e, a partir de então, passou por intenso processo de decréscimo populacional, ligado principalmente ao componente migratório ocorrido no meio rural e, mais recentemente, nas áreas urbanas (Magalhães, 1999). Em decorrência dessa dinâmica de redistribuição espacial da população, a região mantém como centros mais populosos os municípios de Paranavaí, Umuarama e Cianorte (Ipardes, 2003). Como resultado desse processo de urbanização, predominam na Mesorregião os pequenos núcleos urbanos, a maioria com até 20 mil habitantes (Tabela 1). Apenas Paranavaí, Umuarama e Cianorte apresentam população entre 50 mil e 100 mil habitantes.

A definição desses três municípios também foi fruto da existência de plano diretor por mais de um ano, bem como por já possuírem alguma experiência em planejamento urbano, por exemplo, os PLUOS, e por já terem criados seus Conselhos do Plano Diretor (UFPR, 2009).

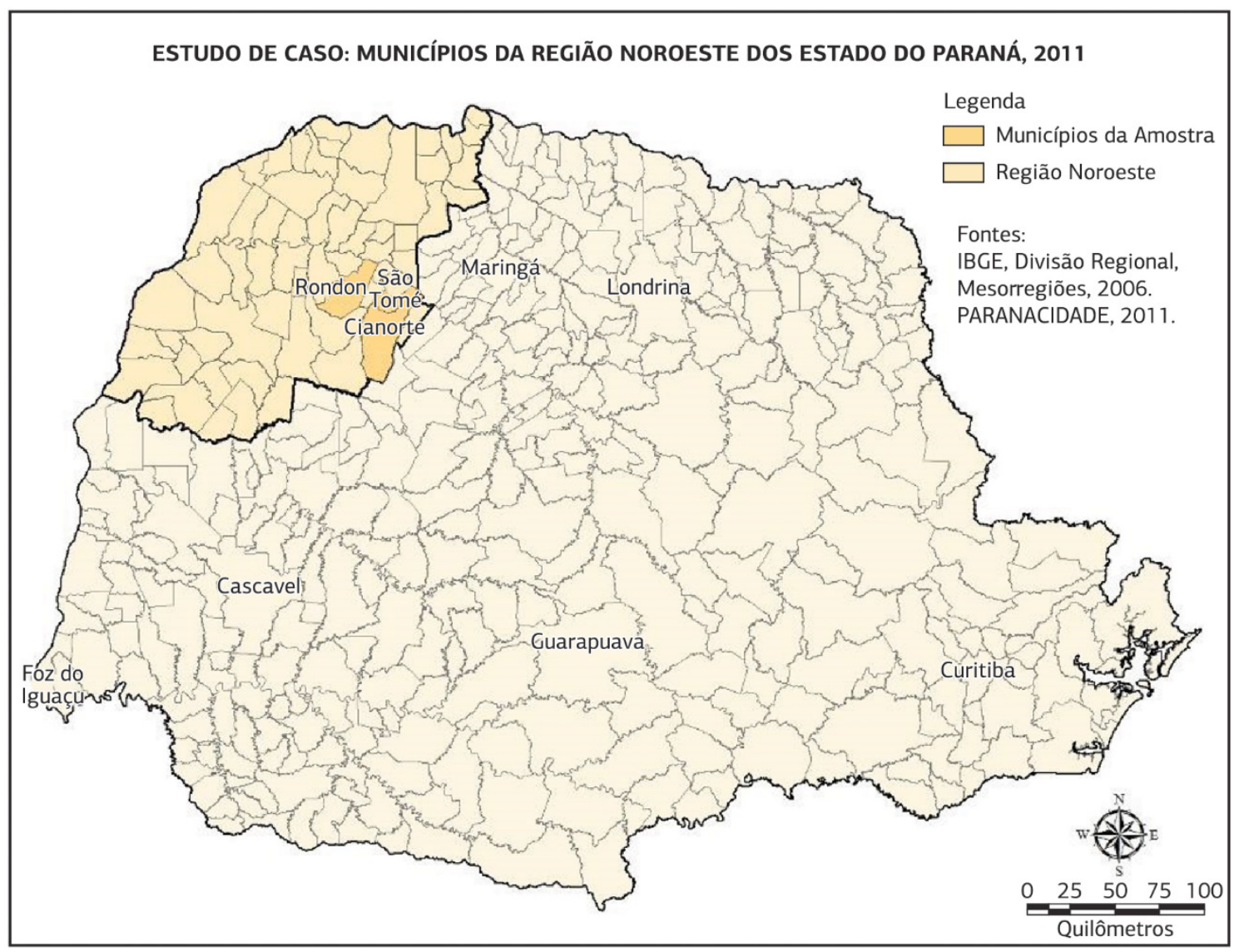

Figura 1 - Mesorregião Noroeste, com destaque para os municípios do Estudo de Caso Fonte: Paranacidades (2011). 


\section{O município de Cianorte e seu Plano Diretor Municipal}

O município de Cianorte localiza-se na Mesorregião Noroeste do estado do Paraná e conta com dois distritos, São Lourenço e Vidigal, em uma área de $773 \mathrm{~km}^{2}$. Segundo o Censo IBGE 2010, sua população total era de 69.962 habitantes (IBGE, 2010).

0 município de Cianorte foi elevado à categoria de município em 1955 e obteve grande progresso econômico nos primeiros anos de sua criação, classificando-se como centralidade de nível médio na rede de cidades da Mesorregião Noroeste, junto com Paranavaí e Umuarama. Já em 2000, Cianorte foi se consolidando como polo nacional de confecções, reforçando seu papel regional, o que a tornou referência em áreas como educação, saúde, serviços de comércio varejista, entre outros. Houve um aumento significativo de sua população, em especial na década de 1990, contrariando a tendência de decréscimo populacional da Mesorregião Noroeste (Tabela 2).

Tabela 1 - Número de Municípios por Faixa de Habitantes, na Mesorregião Noroeste - 2000 e 2010

\begin{tabular}{lcc}
\hline \multirow{2}{*}{$\begin{array}{c}\text { Faixa de Populaç̃o Total } \\
\text { (Habitantes) }\end{array}$} & \multicolumn{2}{c}{ Número de Municípios } \\
\cline { 2 - 3 } & $\mathbf{2 0 0 0}$ & $\mathbf{2 0 1 0}$ \\
\hline De 0 a 5.000 & 20 & 19 \\
De 5.001 a 10.000 & 23 & 29 \\
De 10.001 a 20.000 & 13 & 13 \\
De 20.001 a 40.000 & 3 & 3 \\
Acima de 40.000 & 3 & 3 \\
\hline
\end{tabular}

Fonte: Censo Demográfico (IBGE, 2000, 2010).
O Plano Diretor de Cianorte foi aprovado em 2006, não tendo ocorrido emendas ou polêmicas significativas, apenas foram solicitadas, por parte dos vereadores, várias informações para melhor compreensão das leis.

Da síntese do diagnóstico resultou a identificação de algumas deficiências e potencialidades que orientaram as demais fases de trabalho do plano diretor. Entre os principais aspectos identificaram-se: dinâmica demográfica positiva; grande suscetibilidade à erosão do solo em algumas áreas; existência de ocupações irregulares; deficiência na infraestrutura, como o serviço de coleta e tratamento de esgoto, não oferecido a $46,72 \%$ da população.

A nova legislação urbana contemplou leis e códigos decorrentes de planos anteriores, como o PLUOS de $1988 \mathrm{e}$ o Plano Diretor de 1995, e apresenta alguns instrumentos do Estatuto da Cidade em fase de regulamentação: outorga onerosa do direito de construir, transferência do direito de construir, direito de preempção, estudo de impacto de vizinhança, bem como zonais especiais de interesse social (Quadros 1 e 2 ).

\section{O município de Rondon e seu Plano Diretor Municipal}

0 município de Rondon, localizado na Mesorregião Noroeste e na Microrregião de Cianorte, possui área total de $556 \mathrm{~km}^{2}$ e população total, conforme Censo IBGE 2010, de 9.005 habitantes, com taxa de urbanização de 80\% (IBGE, 2010).

A aprovação do Plano Diretor ocorreu em 2008, não tendo havido propostas de emendas, situação atribuída ao fato que os vereadores participaram de

Tabela 2 - Evolução Demográfica ocorrida no período 1960-2010

\begin{tabular}{cccccc}
\hline & População & \multicolumn{2}{c}{ População Urbana } & \multicolumn{2}{c}{ População Rural } \\
\cline { 2 - 6 } Ano & Total & Abs. & $\%$ & Abs. & $\%$ \\
\hline 1960 & 31.987 & 4.000 & 12,5 & 27.987 & 87,5 \\
1970 & 52.532 & 23.518 & 45 & 29.014 & 55 \\
1980 & 48.797 & 28.797 & 59 & 19.998 & 41 \\
1991 & 49.849 & 37.850 & 76 & 11.996 & 24 \\
2000 & 57.401 & 49.644 & 87 & 6.785 & 13 \\
2010 & 69.962 & 62.282 & 89 & 7.680 & 14 \\
\hline
\end{tabular}

Fonte: UC VILELA - Plano Diretor de Cianorte (UC VILELA, 2009). 
Quadro 1 - Legislação Urbana de Cianorte, 2011

\begin{tabular}{cc}
\hline Leis propostas & Leis aprovadas \\
\hline Lei do Plano Diretor & $2.745-2006$ \\
Lei do Perímetro Urbano & $2.777-2006$ \\
Lei de Zoneamento & $2.747-2006$ \\
Lei de Parcelamento & $2.748-2006$ \\
Código Obras & $2.746-2006$ \\
Código Posturas & $2.749-2006$ \\
Lei Sistema Viório & $2.778-2006$ \\
\hline
\end{tabular}

Fonte: Prefeitura Municipal de Cianorte (Prefeitura Municipal, 2011 la). Nota: Organizado pelos autores (2011).

Quadro 2 - Instrumentos regulamentados ou em processo de regulamentação

\begin{tabular}{ll}
\hline \multicolumn{1}{c}{ Instrumentos } & \multicolumn{1}{c}{ Lei Específica } \\
\hline Outorga Onerosa do Direito de Construir & Em regulamentação \\
Transferência do Direito de Construir & Em regulamentação \\
Direito de Preempção & Em regulamentação \\
Estudo de Impacto de Vizinhança & Autoaplicável \\
Zonas Especiais de Interesse Social & $3.457 / 10 ; 3.554 / 10 ; 3.499 / 10 ;$ \\
& $3.530 / 10 ; 3.507 / 10$ \\
\hline
\end{tabular}

Fonte: Prefeitura Municipal de Cianorte (Prefeitura Municipal, 201 la).

Nota: Organizado pelos autores (2011).

todas as reuniões e das audiências públicas. Após aprovado o plano, foi criado por decreto o Conselho Municipal de Planejamento e Gestão Territorial.

No período de 2008 a 2011, desde a aprovação do plano, a equipe técnica procurou obedecer o Plano Diretor, em especial na aprovação dos novos loteamentos e de projetos para a execução de obras, ou seja, muitas rotinas foram incorporadas ao dia a dia da equipe municipal, em especial na Secretaria de Obras. Conjuntamente com o plano diretor foram aprovadas diversas leis como: Lei do Perímetro Urbano, Lei de Zoneamento, Lei de Parcelamento do Solo, Código de Obras, Código de Posturas e Lei do Sistema Viário (Quadro 3).

Entre as leis mais utilizadas pela administração municipal está a Lei de Zoneamento, aprovada sob o número 1.393/2008, e além do conjunto básico de leis urbanísticas, destacaram-se alguns instrumentos
Quadro 3 - Legislação Urbana de Rondon

\begin{tabular}{cc}
\hline Leis Propostas & Leis Aprovadas \\
\hline Lei do Plano Diretor & $1.391 / 2008$ \\
Lei do Perímetro Urbano & $1.392 / 2008$ \\
Lei de Zoneamento & $1.393 / 2008$ \\
Lei de Parcelamento & $1.394 / 2008$ \\
Código de Obras & $1.396 / 2008$ \\
Código de Posturas & $1.397 / 2008$ \\
Lei do Sistema Viário & $1.395 / 2008$ \\
\hline
\end{tabular}

Fonte: Prefeitura Municipal de Rondon (Prefeitura Municipal, 2011b).

Nota: Organizado pelos autores (2011).

do Estatuto, como: do parcelamento, edificação ou utilização compulsórios; do IPTU progressivo no tempo; da desapropriação com pagamento em títulos da dívida pública; e do consórcio imobiliário. Incorporou ainda os demais instrumentos, como direito de preempção, outorga onerosa do direito de construir, operações urbanas consorciadas, direito de superfície, estudo de impacto de vizinhança e a criação de um fundo de desenvolvimento urbano. 0 Quadro 4 mostra a relação entre os instrumentos jurídicos e urbanísticos e suas áreas de aplicação em conformidade com a nova proposta de zoneamento urbano.

Com relação aos instrumentos constantes no plano, apesar de todos terem sido descritos na Lei do Plano Diretor, as zonas especiais de interesse social aparecem com mais frequência. Outros instrumentos instituídos foram da concessão de uso especial e o consórcio imobiliário.

Em relação à Gestão Democrática, desde sua elaboração o plano contou com auxílio de uma equipe técnica municipal e uma Comissão de acompanhamento, constituída por representantes da administração municipal e da sociedade civil organizada.

\section{O Município de São Tomé e seu Plano Diretor Municipal}

0 município de São Tomé, localizado na Mesorregião Noroeste Paranaense, desmembrou-se de Cianorte e foi elevado à condição de município em 1960. Possui área de $219,72 \mathrm{~km}^{2}$ e tem uma população total de 5.349 habitantes (Tabela 3) (IBGE, 2010). 
Quadro 4 - Novos instrumentos legais propostos pelo Plano Diretor Municipal e sua aplicaçã̃o

\begin{tabular}{|c|c|c|}
\hline Instrumento & Aplicação & Lei Específica \\
\hline $\begin{array}{l}\text { Do Parcelamento, Edificação ou Utilização Compulsórios; } \\
\text { Do IPTU Progressivo no Tempo; Da Desapropriação com } \\
\text { Pagamento em Títulos da Dívida Pública }\end{array}$ & $\begin{array}{l}\text { Macrozonas: } \\
\text { Residencial consolidada } \\
\text { De expansão residencial } \\
\text { Residencial de qualificação urbana } \\
\text { Comercial } \\
\text { De expansão comercial } \\
\text { Industrial não poluitiva }\end{array}$ & \\
\hline Do Consórcio Imobiliário & $\begin{array}{l}\text { Macrozonas: } \\
\text { Residencial consolidada } \\
\text { De expansão residencial } \\
\text { Residencial de qualificação urbana } \\
\text { Comercial } \\
\text { De expansão comercial } \\
\text { Industrial não poluitiva }\end{array}$ & $\begin{array}{l}\text { Regulamentada a Lei de Concessão de Uso Especial, } \\
\text { Lei no } 1.335 / 2007 \text {, no loteamento São João, porém, } \\
\text { como consta parceria com o proprietário, foi utilizado o } \\
\text { Consórcio Imobiliário }\end{array}$ \\
\hline Lei da Outorga Onerosa do Direito de Construir & A definir em lei específica & \\
\hline Lei da Transferência do Direito de Construir & A definir por órgão competente e aprovado pelo Conselho & \\
\hline Lei do Direito de Preempção & A definir em lei específica & \\
\hline \multicolumn{3}{|l|}{ Lei de Estudo de Impacto de Vizinhança } \\
\hline Zonas Especiais de Interesse Social (ZEIS) & A definir em lei específica & $\begin{array}{l}\text { Foram criadas as ZEIS para os loteamentos Bela } \\
\text { Vista, Santo Antônio, São João (mas não possuem lei } \\
\text { espećíica) }\end{array}$ \\
\hline
\end{tabular}

Fonte: UC VILELA, Plano Diretor Municipal de Rondon (UC VILELA, 2006a).

Nota: Organizado pelos autores (2011).

Tabela 3 - Distribuição da população no território nas décadas de 1990, 2000 e 2010

\begin{tabular}{llll}
\hline Indicador & $\mathbf{1 9 9 1}$ & $\mathbf{2 0 0 0}$ & $\mathbf{2 0 1 0}$ \\
\hline População Total & 5.115 & 5.045 & 5.349 \\
População Urbana & 2.576 & 3.744 & 4.446 \\
População Rural & 2.539 & 1.301 & 903 \\
\hline
\end{tabular}

Fonte: Plano Diretor Municipal de São Tomé (UC VILELA, 2006b).

O município de São Tomé foi um dos integrantes do plano de colonização da CMNP, a partir de um pequeno núcleo. Foi criado em 1954 e teve seu maior desenvolvimento no começo da década de 1960. Nas décadas de 1980 e 1990 foram acrescidos três loteamentos nas direções norte, oeste, leste e sul da área urbana, e na década de 2000 a expansão se deu em todas as direções. Sua evolução caracteriza-se pelo pouco critério em sua distribuição, em todos os quadrantes da cidade.

O Plano Diretor de São Tomé foi aprovado em 2006, sem emendas significativas, mas uma aprovação foi lenta, tendo demorado em torno de nove meses. 0 plano propôs, em suas diretrizes, um macrozoneamento com destaque para as áreas especiais dos eixos rodoviários, as áreas de risco geológico e de preservação ambiental. Foram mantidas e atualizadas as leis urbanas básicas, que já constavam no PLUOS vigente até a aprovação do novo plano.

Quanto aos instrumentos do Estatuto, o Quadro 5 mostra os que foram propostos, bem como as áreas em que esses instrumentos podem ser aplicados.

Alguns instrumentos necessitam de regulamentação específica, o que já está ocorrendo para os instrumentos das Zonas Especiais de Interesse Social (ZEIS) e a Concessão de Uso e Consórcio Imobiliário. Destaca-se a aplicação do instrumento da ZEIS em áreas de ocupação irregulares em Área de Proteção Ambiental (APP). Também foi criada uma zona especial em área de interesse turístico; foi criado o Fundo Municipal de Habitação de Interesse Social, gerenciado pelo Conselho e elaborado um Plano Local de Habitação de Interesse Social. 
Quadro 5 - Novos instrumentos legais propostos e sua aplicação - PDM São Tomé

\begin{tabular}{|c|c|}
\hline Instrumento & Aplicação \\
\hline $\begin{array}{l}\text { Do Parcelamento, Edificacãão ou Utilizaccão Compulsórios; Do IPTU Progressivo no Tempo; } \\
\text { Da Desapropriação com Pagamento em Títulos da Dívida Pública }\end{array}$ & $\begin{array}{l}\text { Macrozona residencial a densificar e de expansão } \\
\text { Macrozona comercial a densificar e de expansão } \\
\text { Macrozona industrial } \\
\text { Setores Especiais }\end{array}$ \\
\hline Do Consórcio Imobiliário & $\begin{array}{l}\text { Macrozona residencial a densificar } \\
\text { Macrozona de expansão residencial } \\
\text { Macrozona residencial de contenção } \\
\text { Macrozona comercial a densificar } \\
\text { Macrozona de expansão comercial } \\
\text { Macrozona industrial }\end{array}$ \\
\hline Lei da Outorga Onerosa do Direito de Construir & Lei espećfica municipal \\
\hline Lei da Transferência do Direito de Construir & A ser definido pelo órgão competente e aprovado pelo Conselho \\
\hline Lei do Direito de Preempç̃̃o & Lei espećifica municipal \\
\hline $\begin{array}{l}\text { Lei de Estudo de Impacto de Vizinhança } \\
\text { Das Operaçõos Urbanas Consorciadas }\end{array}$ & $\begin{array}{l}\text { Autoaplicável } \\
\text { Lei espećifica }\end{array}$ \\
\hline Zonas Especiais de Interesse Social (ZE|S) & Lei espećífica \\
\hline
\end{tabular}

Fonte: UC VILELA, PDM de São Tomé (UC VILELA, 2006b).

Nota: Organizado pelos autores (2011).

Na questão de Gestão Democrática, criou-se o Conselho Municipal de Desenvolvimento Urbano, Planejamento e Gestão Territorial. Quanto à Gestão Municipal, após a aprovação do plano, algumas ações foram implementadas e demandaram aprimoramento por parte da Gestão, destacando-se a aprovação de novos loteamentos, que levaram em conta parâmetros urbanísticos estabelecidos na legislação, em especial nas leis de Zoneamento, Parcelamento do Solo, Lei do Sistema Viário e Código de Obras e de Posturas.

Ao analisarmos individualmente os processos de implementação dos estudos de caso, foi possível constatar que os três municípios, independentemente do seu porte, estrutura técnica e limitações, estão promovendo avanços, na medida do possível, considerando-se os três temas adotados no desenvolvimento da pesquisa.

\section{Legislação e Instrumentos de Indução do Desenvolvimento e Regularização Fundiária}

Nos municípios de Rondon e São Tomé predomina a aplicação da legislação urbana básica, como a Lei do Perímetro Urbano, a de Zoneamento e a de Parcelamento. No caso de São Tomé, essas leis já estavam integradas ao processo de planejamento, apesar de não serem respeitadas na íntegra. Com a aprovação do novo PDM e a criação do Conselho, esse controle passou a ser mais rígido. 0 perímetro urbano foi ampliado para a incorporação das ZEIS.

No caso de Rondon, que não possuía legislação anterior, o processo estava ocorrendo com mais dificuldade, porém com maior envolvimento da equipe local, sendo que todos os novos loteamentos passaram pela anuência do Conselho. Foi surpresa o fato de que estavam sendo regulamentados, além do instrumento das ZEIS (para novos conjuntos ou para regularização), o instrumento do Consórcio Imobiliário e a Concessão de Uso Especial.

Trata-se de municípios com uma legislação básica que, a princípio, supriria suas necessidades, visto que possuem gabaritos de edificações de no máximo dois pavimentos, com uma rua principal que acumula todo o comércio local. Porém, como todas as nossas cidades, apresentam áreas com ocupações irregulares, havendo necessidade de definição de áreas para habitação voltada à população de baixa renda, não adoção de aspectos de mobilidade urbana, entre outros. Isso explica a opção pela aplicação dos instrumentos citados. 


\section{Município de Cianorte}

O município de Cianorte já possuía cultura de planejamento, não só pela sua origem como cidade projetada pela CMNP, mas também pela existência de Plano Diretor desde a década de 1980. Com o novo PDM, são evidentes os avanços na aplicação tanto da legislação básica quanto dos instrumentos do Estatuto: (i) Zonas Especiais de Interesse Social; (ii) Consórcio Imobiliário, nos lotes da CMNP, para a implantação dos projetos de Revitalização do Centro Antigo e do Pátio Ferroviário; (iii) Direito de Preempção (em trecho de rua para alargamento futuro); e (iv) Estudo de Impacto de Vizinhança. A nova Lei de Zoneamento reafirmou o direcionamento e as limitações anteriores, ou seja, não ocupação de áreas ao sul, a não ocupação das áreas de risco geológico e preservação do Cinturão Verde da cidade.

\section{Gestão Democrática}

\section{Municípios de Rondon e São Tomé}

Os dois municípios criaram seus Conselhos para a implementação de seus Planos Diretores Municipais, porém, não possuíam agenda de reuniões para temas relacionados à questão do desenvolvimento; reuniam-se somente quando existia uma demanda específica. Apenas uma audiência pública foi realizada em São Tomé, após a aprovação do PDM, situação que refletia dificuldade em promover a participação da comunidade na definição do desenvolvimento desses municípios.

\section{Município de Cianorte}

Apesar de já possuir uma cultura de planejamento urbano, constatou-se que somente após a aprovação do novo Plano Diretor Municipal a prática de reunir o Conselho incorporou-se à rotina da administração municipal, por exemplo, para aprovação de novos loteamentos, projetos e obras de impacto, como a Revitalização do Centro e do Pátio Ferroviário.

\section{Processo de Planejamento Municipal}

\section{Municípios de Rondon e São Tomé}

Identificou-se que não ocorreram alterações nas estruturas administrativas dos dois municípios para a implementação dos Planos Diretores Municipais, estando sob a responsabilidade de setores já consolidados da administração municipal. Nenhum desses municípios, à época da pesquisa, dispunha de profissional com formação na área de urbanismo para acompanhar a implementação dos Planos Diretores, porém avançaram em alguns itens. Em Rondon, por exemplo, todos os loteamentos aprovados após o PDM passaram pela anuência do Conselho; foram adotados modelos de procedimentos para aprovação de projetos, loteamentos, execução de obras e normatização.

Em São Tomé, parte do acompanhamento do PDM tinha sido terceirizada, solução encontrada devido às dificuldades para sua implementação. No entanto, esta situação estava sendo revista, devendo a administração municipal assumir o desafio de incorporar uma rotina que dê continuidade aos avanços já obtidos pelo serviço terceirizado, como: (i) a criação do Conselho e do Núcleo de Planejamento; (ii) as prioridades municipais, definidas para 2011, passaram pela aprovação do Conselho; (iii) aprovação de Leis Específicas para a utilização de instrumentos, como as ZEIS, por exemplo.

\section{Município de Cianorte}

Dos municípios estudados, foi em Cianorte que a implementação do Plano Diretor Municipal estava em processo mais adiantado, exercendo seu papel como indutor do desenvolvimento. Muitas ações estavam em andamento: a parceria entre a Prefeitura e a CMNP para a aprovação de projetos, a revitalização do Centro Antigo e do Pátio Ferroviário, a contratação de profissionais para implementar o PDM e a compatibilização de emissão de alvarás e as leis urbanísticas, como o zoneamento, parcelamento e obras, entre outras ações.

\section{Conclusão}

Nestes 13 anos de aplicação do Estatuto da Cidade, ficou evidente o esforço da administração estadual e o engajamento dos municípios paranaenses no processo de planejamento e de gestão urbana, destacando-se o pioneirismo do estado ao ampliar a obrigatoriedade de elaboração dos PDMs. Conforme constatado, seja pela necessidade de acesso aos recursos do tesouro do Estado, seja pela necessidade de planejamento, do total de 399 municípios paranaenses, 363 municípios já possuem plano diretor, ou seja, 90\% dos municípios, e 316 destes 
planos estavam aprovados nas Câmaras Municipais. Apesar deste quadro positivo, poucos municípios regulamentaram os instrumentos urbanísticos do Estatuto da Cidade.

Os estudos de caso, em três municípios da mesorregião Noroeste do estado - Cianorte, Rondon e São Tomé -, apresentaram aspectos importantes para o entendimento do processo de implementação dos planos diretores. Para Cianorte, a implementação do PDM estava contribuindo para a melhoria da gestão urbana, com avanços em três frentes: aplicação da legislação e instrumentos do Estatuto, exercício da gestão democrática e implantação do processo de planejamento municipal. Essa situação se justifica pela existência de uma cultura de planejamento e de uma estrutura gerencial mais consolidada que nos outros municípios pesquisados. No município de Rondon, observou-se que a implementação do PDM também estava contribuindo para a gestão urbana, destacando-se avanços na aplicação de instrumentos de desenvolvimento e regularização fundiária e nos processos de planejamento municipal, porém era limitado o avanço na gestão participativa. Também no município de São Tomé, a implementação do PDM destacou-se nos aspectos ligados à aplicação dos instrumentos do Estatuto e no processo de planejamento, apesar de os aspectos de participação necessitarem, assim como em Rondon, de reforço por parte da administração municipal.

A pesquisa, ao buscar identificar a importância da implementação do PDM no processo de gestão urbana, em municípios do Estado do Paraná, constatou que os PDMs estão sendo implantados, resguardadas as limitações, possibilitando o desenvolvimento dos municípios. Conduziu à percepção de que os PDMs avançaram no tratamento das questões sociais. 0 estudo revelou que a aplicação da legislação e dos instrumentos do Estatuto é exequível, desde que sejam respeitadas as necessidades de cada município.

Quanto à revisão desses planos, aproxima-se o período de os municípios reverem seus Planos Diretores Municipais, no entanto, antes de fazê-lo, cabe a todas as instâncias envolvidas no processo de revisão e implementação desses planos uma avaliação das experiências adquiridas no período pós-Estatuto, de modo a poder realizar os ajustes necessários.

\section{Referências}

Bacellar de Araújo, T., \& Bezerra, M. L. (1999). Experiência recente em planejamento regional: os casos das Associações de Municípios do Setentrião e do Oeste do Paraná. Curitiba: ParanaCidade.

Brasil. (2004). Ministério das Cidades. Plano Diretor Participativo: guia para elaboração pelos municípios e cidadãos. Brasília, DF: Ministério das Cidades.

Cymbalista, R., \& Bueno, L. M. M. (2007). Planos Diretores Municipais: novos conceitos de planejamento territorial. São Paulo: Annablume.

Endlish, Â. M. (2009). Pensando os papéis e significados das pequenas cidades. São Paulo: UNESP.

Faraco, J. L. (2010). Plano Diretor Municipal de Alto Paraná. Curitiba: ParanaCidade.

Fundação de Assistência aos Municípios do Paraná FAMEPAR. (1992). Os planos de uso e ocupação do solo urbano. Curitiba: FAMEPAR.

Instituto Brasileiro de Geografia e Estatística - IBGE. (2000). Censo Demográfico 2000. Rio de Janeiro: IBGE. Recuperado em 14 agosto 2014, de http:// www.ibge.gov.br

Instituto Brasileiro de Geografia e Estatística - IBGE. (2010). Censo Demográfico 2010. Rio de Janeiro: IBGE. Recuperado em 14 agosto 2014, de http:// www.ibge.gov.br

Instituto Paranaense de Desenvolvimento Econômico e Social - IPARDES. (2003). Leituras Regionais. Curitiba: IPARDES.

Magalhães, F., Fo. (1999). Região da Associação dos Municípios do Oeste Paranaense (AMOP): características e perspectivas de desenvolvimento (Séries Técnicas). Curitiba: ParanaCidade.

Meirelles, H. L. (1985). Direito administrativo brasileiro. São Paulo: Editora RT.

Paraná (2006, 25 de julho). Lei n. 15.229 de 25 de julho de 2006. Dispõe sobre normas para execução do sistema das diretrizes e bases do planejamento e desenvolvimento estadual, nos termos do art. 141, da Constituição Estadual. Brasília: Diário Oficial do Estado.

ParanaCidade, Serviço Social Autônomo (2003a). Termo de Referência para Elaboração dos Planos Diretores Municipais. Curitiba: ParanaCidade. 
ParanaCidade, Secretaria de Estado do Desenvolvimento Urbano (2003b). Política Estadual de Desenvolvimento Urbano. Curitiba: SEDU.

ParanaCidade, Serviço Social Autônomo (2011). Situação dos Planos Diretores Municipais. Curitiba: ParanaCidade.

ParanaCidade, Serviço Social Autônomo (2012a). Apresentação da situação dos planos diretores municipais paranaenses para o CONCIDADES -PR. Curitiba: ParanaCidade.

ParanaCidade, Serviço Social Autônomo (2012b). Mapa da situação dos Planos Diretores Municipais. Curitiba: ParanaCidade.

ParanaCidade, Serviço Social Autônomo (2012c). Matriz Planos Diretores Municipais. Curitiba: ParanaCidade.

Prefeitura Municipal (2011a) Pesquisa social. Cianorte: Prefeitura Municipal. Recuperado em 11 de agosto de 2011, de http://www.cianorte.pr.gov.br/
Prefeitura Municipal (2011b). Pesquisa social. Rondon: Prefeitura Municipal. Recuperado em 11 de agosto de 2011, de http://www.rondon.pr.gov.br/

Santos, O. A., Jr., \& Montandon, D. T. (2011). Os Planos diretores municipais pós-Estatuto da Cidade: balanço crítico e perspectivas. Rio de Janeiro: Observatório das Metrópoles - IPPUR/UFRJ.

UC VILELA (2006a). Plano Diretor de Rondon. Curitiba: ParanaCidade.

UC VILELA (2006b). Plano Diretor de São Tomé. Curitiba: ParanaCidade.

UC VILELA (2009). Plano Diretor de Cianorte. Curitiba: ParanaCidade.

Universidade Federal do Paraná - UFPR. (2009). Relatório estadual: estado do Paraná. Curitiba: UFPR.

Recebido: Mar. 04, 2014

Aprovado: Out. 01, 2014 